\title{
Metabolism of Immunoreactive
}

\section{Parathyroid Hormone in the Dog}

\author{
THE ROLE OF THE KIDNEY AND THE \\ EFFECTS OF CHRONIC RENAL DISEASE
}

\author{
Keith A. Hruska, Robert Kopelman, W. Ernest Rutherford, \\ SaUlo Klahr, and Eduardo Slatopolsky with the technical assistance of \\ allen Greenwalt, Toby Bascom, and JoAnn Markham
}

From the Renal Division, Department of Medicine, Washington University School of Medicine, St. Louis, Missouri 63110

\begin{abstract}
A B S T R A C T The role of the kidney in the metabolism of parathyroid hormone (PTH) was examined in the dog. Studies were performed in awake normal and uremic dogs after administration of bovine parathyroid hormone (b-PTH) or synthetic amino terminal tetratricontapeptide of b-PTH (syn b-PTH 1-34). The renal clearance of immunoreactive $\mathrm{PTH}$ was determined from the product of renal plasma flow and the percent extraction of $\mathrm{PTH}$ immunoreactivity by the kidney. Blood levels of circulating immunoreactive $\mathrm{PTH}$ were determined by radioimmunoassay.

The normal dog kidney extracted $20 \pm 1 \%$ of the immunoreactive $\mathrm{b}-\mathrm{PTH}$ delivered to it, and renal clearance (RC) of immunoreactivity was $60 \mathrm{ml} / \mathrm{min}$. When $\mathrm{RC}$ was compared to an estimate of total metabolic clearance (MCR) of immunoreactivity, it accounted for $61 \%$ of the total. Both MCR and RC were markedly decreased in dogs with chronic renal disease. However, the percent extraction of immunoreactive $\mathrm{PTH}$ was unchanged in chronic renal disease, and the observed decrease in $\mathrm{RC}$ was due to changes in renal plasma flow. The largest portion of the reduction in total MCR was accounted for by the decrease in $\mathrm{RC}$, and there was no compensation for the decrease in $\mathrm{RC}$ by extrarenal sites of PTH metabolism.
\end{abstract}

Dr. Hruska is the recipient of a research fellowship from the National Kidney Foundation.

This work was presented in part at the annual meeting of the American Society of Nephrology in Washington, D. C., November 1973.

Received for publication 3 September 1974 and in revised form 27 December 1974.
Gel filtration of pooled serum samples from normal and chronic renal disease dogs demonstrated a rapid conversion of injected intact b-PTH into immunologically detectable peptide fragments of both the carboxyl (C) and amino (N) terminal portion of the PTH molecule. The elution pattern of samples from dogs with renal disease demonstrated higher levels of each immunologically detected peptide and especially C-terminal fragments throughout the time of study.

Studies with the biologically active $\mathrm{N}$-terminal PTH fragment (syn b-PTH 1-34) demonstrated a higher renal extraction of $37 \pm 3 \%$ and a more rapid total MCR than was seen with b-PTH. The effects of renal disease on the clearance rates of syn b-PTH 1-34 were similar to those seen with b-PTH except that there was a more marked decrease in extrarenal clearance of syn b-PTH 1-34. Extrarenal syn b-PTH 1-34 clearance was $133 \pm 9$ $\mathrm{ml} / \mathrm{min}$ in normals and $58 \pm 14 \mathrm{ml} / \mathrm{min}$ in dogs with renal disease.

These studies indicate that the kidney plays an important role in the metabolism of PTH in vivo. They describe the impaired degradation of PTH seen in uremia, and they suggest that this may be a factor that contributes to the high levels of circulating immunoreactive $\mathrm{PTH}$ seen in chronic renal disease. They also suggest an effect of renal disease on PTH metabolism at sites other than the kidney.

\section{INTRODUCTION}

Secondary hyperparathyroidism is a nearly universal complication of chronic renal disease. Hypocalcemia re-

The Journal of Clinical Investigation Volume $56 \quad$ July 1975.39-48 
sulting from phosphate retention and calcium malabsorption has been shown to cause overproduction of parathyroid hormone $(\mathrm{PTH})^{\mathbf{1}}$ in advancing renal disease (1-3). The possibility that impaired degradation of PTH also contributes to the high blood levels of the hormone in chronic renal disease has not been adequately examined.

Previous studies have demonstrated that the kidney is able to degrade $\mathrm{PTH}$ in vitro $(4,5)$. Studies after nephrectomy or the development of end-stage renal disease have shown a prolonged half-time of disappearance for administered radiolabeled PTH suggesting that the kidney plays an important role in PTH metabolism in vivo $(6,7)$. However, the renal contribution to $\mathrm{PTH}$ metabolism under normal conditions has not been quantified, and the effects of uremia on the renal handling of PTH have not been investigated.

PTH has recently been shown to circulate not only as the intact hormone but also as carboxy terminal (C-terminal) $(8,9)$ and amino terminal (N-terminal) fragments of the molecule (10). The half-lives of the fragments in the circulation are widely divergent. Synthetic bovine $\mathrm{N}$-terminal is very short lived with a half-life of approximately $5 \mathrm{~min}$ in the rabbit (11), while C-terminal fragments devoid of biologic activity have longer half-lives in the range of hours $(9,11)$. Since the rate of degradation of intact PTH and its fragments appear to differ widely, any description of PTH metabolism must address itself to the complex problem of separating and describing the rate of metabolism of each species in the circulation.

The studies reported herein were designed to examine the contribution of the dog kidney in vivo to the metabolism of PTH and its fragments. The renal contribution to the total metabolic clearance rate (MCR) of immunoreactive $\mathrm{PTH}$ was determined in normal and uremic dogs. The results of this study indicate that the kidney plays an important role in the metabolism of PTH and its fragments in vivo and suggest that decreased degradation of the hormone may contribute to the elevated PTH levels observed in renal insufficiency.

\section{METHODS}

Preparation of dogs. Studies were performed in female mongrel dogs weighing $12-24 \mathrm{~kg}$ who had free access to water and were fed standard Purina dog chow. Before study, the left kidney of each dog was explanted to a subcutaneous position on the left flank by a modification of previously described techniques (12). Through a flank incision the renal vein was traced from the renal hilum to

\footnotetext{
${ }^{1}$ Abbreviations used in this paper: b-PTH, bovine parathyroid hormone; C-terminal, carboxyl terminal; MCR, metabolic clearance; N-terminal, amino terminal; PAH, para-aminohippurate; PTH, parathyroid hormone; RC, renal clearance; RIA, radioimmunoassay; syn b-PTH 1-34, synthetic amino terminal tetratricontapeptide.
}

the inferior vena cava, and all veins of nonrenal origin connecting with the renal vein were ligated. The proximal renal vein was placed in semicircular Teflon sheath $2-3 \mathrm{~cm}$ long. The sheath was immobilized by suturing to the surrounding connective tissue and then was sutured to subcutaneous tissue. Fixation of the semicircular sheath subcutaneously allowed localization and percutaneous catherization of the renal vein but did not affect glomerular filtration rate or renal plasma flow.

Chronic renal disease was induced in dogs with explanted kidneys by two methods. In the first, most of the branches of the left renal artery were ligated during surgery before explantation. The second method utilized the induction of pyelonephritis in a previously explanted kidney (13). Both methods employed contralateral nephrectomy as a final step, leaving only the diseased kidney as a source of renal function. After the final surgical procedure and 2-3 wk of recovery, the dogs were studied in the awake resting state.

Study protocol. Food was removed $12 \mathrm{~h}$ before study, but access to water was continued. A femoral arterial catheter for blood sampling was placed by means of percutaneous puncture of the artery with a needle through which a guide wire was directed. Then a polyethylene catheter was directed over the guide wire into the vessel lumen to the approximate level of the renal artery. The left renal vein was catheterized percutaneously. A hind leg vein catheter was placed for infusion of solutions and a bladder catheter was placed for collection of urine. After priming doses of $50 \mathrm{mg} / \mathrm{kg}$ creatinine and $4-5 \mathrm{mg} / \mathrm{kg}$ para-aminohippurate, a sustaining solution of normal saline with creatinine and paraaminohippurate was administered to maintain creatinine at the level of $10 \mathrm{mg} / 100 \mathrm{ml}$ and para-aminohippurate at a concentration of $1-2 \mathrm{mg} / 100 \mathrm{ml}$. Sustaining solutions were administered through a Holter constant infusion pump, Model RL 175 (Extracorpeal Medical Specialties, Inc., King of Prussia, Penn.), at rates from 1 to $2.5 \mathrm{ml} / \mathrm{min}$.

After an equilibration period, metabolic clearance rates of immunoreactivity were determined by either single injection or constant infusion techniques. In the single injection protocol, arterial samples were obtained at 1-10-min intervals for 3-4 $\mathrm{h}$ after the rapid injection (10 s) of 25-100 $\mu \mathrm{g}$ purified bovine PTH (b-PTH) or $50-100 \mu \mathrm{g}$ synthetic amino terminal tetratricontapeptide of b-PTH (syn b-PTH $1-34$ ) into a hind leg vein. Renal vein samples were collected during the disappearance curve simultaneous to various arterial samples for the calculation of A-V differences. In the constant infusion protocol, the b-PTH or syn b-PTH 1-34 was added in varying amounts to a saline infusion solution under ice so that after $2 \mathrm{~h}$ of equilibration the level oi immunoreactive PTH or syn b-PTH 1-34 was constant, between $2-10 \mathrm{ng} / \mathrm{ml}$. Dog hypoparathyroid serum was also added as a protein carrier to the constant infusion solution to obtain a protein concentration of $1-2 \mathrm{~g} / 100 \mathrm{ml}$. No priming dose of $\mathrm{PTH}$ was administered in the constant infusion studies. Arterial blood levels with less than $5 \%$ variance from each other were used to ascertain the constant level of PTH.

In both experimental protocols, cross-reactivity of endogenous canine PTH with the antiserum to b-PTH, (CH9), was subtracted as a background from all samples. In normal dogs the level of immunoreactive PTH detected by the antiserum to b-PTH was less than $300 \mathrm{pg} / \mathrm{ml}$ using a b-PTH standard curve as a reference. In uremic dogs, immunoreactive PTH ranged from $1-4 \mathrm{ng} / \mathrm{ml}$. During experiments in which the dogs were infused as above, except that PTH was not administered and blood was taken, serum PTH levels did not change significantly. The ade- 
quacy of renal vein sampling was evaluated by para-aminohippurate $(\mathrm{PAH})$ extraction and only samples with 70$80 \% \mathrm{PAH}$ extraction were considered to be without contamination of inferior vena caval blood in normal dogs. In uremic dogs, $\mathrm{PAH}$ extraction determined by renal vein catheterization under direct vision at laporatomy was compared with the extractions obtained in the studies with percutaneous catheterization. The results were the same in both settings.

Source of PTH. Highly purified b-PTH for administration and for the radioimmunoassay (RIA) standard curve was obtained from Inolex Pharmaceuticals, Glenwood, Ill. The specific activity of the purified PTH as determined by the Wilson Company in the Munson bioassay was $900 \mathrm{U} /$ mg. Syn b-PTH 1-34 for administration and RIA standard was obtained from the Beckman Instruments, Inc., Palo Alto, Calif. The specific activity stated by the Beckman Instruments, Inc. in the adenyl cyclase system varied from $800-2,700 \mathrm{U} / \mathrm{mg}$. Both b-PTH and syn 1-34 were reconstituted in $0.2 \%$ acetic acid, $\mathrm{pH} 3.5$, and added to dog hypoparathyroid serum for injection. On gel filtration, both preparations of PTH demonstrated single peak elution patterns of immunoreactivity and for the purposes of the present studies were considered to be pure hormones although the specific activities, as reported by the manufacturers, were less than those reported for purified preparations from other laboratories (14).

Chemical determinations. Creatinine in serum and urine was determined by the Jaffe reaction as described by Folin (15) and adapted for the Technicon Autoanalyzer (Technicon Instruments Corp., Tarrytown, N. Y.). PAH was determined by the method of Harvey and Brothers (16) and phosphate by the methods of $\mathrm{Kraml}$ and Hurst $(17,18)$. Both $\mathrm{PAH}$ and phosphate methods were also adapted for the Technicon Autoanalyzer.

Radioimmunoassay methods. Serum levels of both bPTH and syn b-PTH 1-34 were determined by RIA techniques according to methods described by Reiss and Canterbury and Arnaud, Tsao, and Littledike $(19,20)$. The antiserum ( $\mathrm{CH} 9$ ) was obtained from a cockerel immunized with a preparation of $6 \mathrm{mg}$ b-PTH (TCA precipitate, Wilson Company) in $0.5 \mathrm{ml}$ complete Freund's adjuvant. The immunogen was administered into the foot pad and booster injections were given 14, 30, and every 30 days after the initial injection. The antiserum used in the present studies was obtained after 10 injections and was used in a $1: 15,000$ final dilution. At this dilution, there was significant displacement of tracer binding with $10-20 \mathrm{pg}$ of purified b-PTH.

The regional specificity characteristics of the binding of the $\mathrm{CH} 9$ antiserum to $\mathrm{PTH}$ are portrayed in Fig. 1. As shown, binding of $\left[{ }^{131} \mathrm{I}\right] \mathrm{b}-\mathrm{PTH}$ to the $\mathrm{CH} 9$ antiserum was displaced by increasing amounts of noniodinated b-PTH with less than $10 \%$ tracer binding present after the addition of $300 \mathrm{pg}$ of purified b-PTH (-) . When the CH9 antiserum was preadsorbed with syn b-PTH 1-34, $5 \mathrm{ng} /$ $100 \mu \mathrm{l}$ of an antiserum preparation $1: 3,000$ dilution for 24-48 $\mathrm{h}$ before use at $4^{\circ} \mathrm{C}$, the standard curve of tracer binding displacement was essentially unchanged $(\boldsymbol{\Delta}-\mathbf{\Delta})$. When syn b-PTH 1-34 was used as the noniodinated ligand, there was only a small amount of displacement of the percent $\left[{ }^{131} \mathrm{I}\right] \mathrm{b}-\mathrm{PTH}$ bound with the antiserum $\left(\mathrm{O}_{-}-\mathrm{O}\right)$. This displacement was incomplete even when $800 \mathrm{ng} / \mathrm{ml}$ of syn b-PTH 1-34 was used as the unlabeled ligand. Furthermore, when the $\mathrm{CH} 9$ antiserum was preadsorbed with syn b-PTH $1-34$, there was no displacement of antiserum binding with $\left[{ }^{131} \mathrm{I}\right] \mathrm{b}-\mathrm{PTH}$ by increasing amounts of syn b-PTH 1-34 including very high concentrations $(\triangle--\triangle)$. These studies indicated that the great majority of the antigenic binding sites in the $\mathrm{CH} 9$ antiserum were specific for amino acid sequences $\mathrm{C}$-terminal to position 34 in the b-PTH molecule, and that after preadsorption with syn b-PTH 1-34 the antiserum was $\mathrm{C}$-terminal specific.

The antiserum (CH9N) used in the RIA in studies after the administration of syn b-PTH 1-34 and for the determination of $\mathrm{N}$-terminal immunoreactivity in gel filtration studies was obtained from a cockrel immunized with 400 $\mu \mathrm{g}$ of syn b-PTH 1-34 (Beckman Instruments Inc.) in $0.5 \mathrm{ml}$ of complete Freund's adjuvant. Injections were repeated at days 14,30 , and every 30 days after the initial injection. The antiserum used in the present studies was obtained after seven injections and used at a 1:8,000 final dilution. The standard curve for displacement of $\left[{ }^{131} \mathrm{I}\right]$ syn b-PTH 1-34 bound to antiserum by increasing amounts of syn b-PTH 1-34 is portrayed in Fig. 2. There was significant displacement of iodinated ligand by $10-15 \mathrm{pg}$ of noniodinated syn b-PTH $1-34$ and almost complete displacement by $1.25 \mathrm{ng}(\bullet-\bullet)$. When b-PTH was used to displace bound $\left.{ }^{131} \mathrm{I}\right]$ syn b-PTH $1-34(\mathrm{O}-\mathrm{O})$, more than 10 -fold greater quantities of hormone were required to obtain the same degree of depression in percent binding demonstrated when syn b-PTH 1-34 was employed.

In addition, when the $\mathrm{CH} 9 \mathrm{~N}$ antiserum was preadsorbed with syn b-PTH 1-34, as described above, there was no detectable binding with $\left.{ }^{131} \mathrm{I}\right] \mathrm{b}-\mathrm{PTH}$. These results indicated the specificity of this antiserum for antigenic determinants on the $\mathrm{N}$-terminal portion of the PTH molecule. Also the affinity of the antiserum for binding sites on the $\mathrm{N}$ -

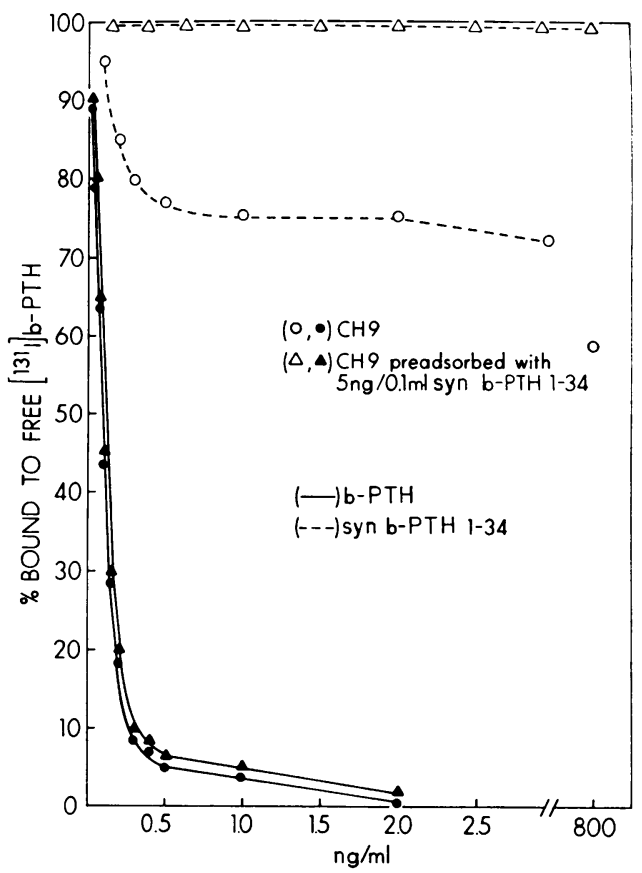

Figure 1 Displacement of $\left[{ }^{131} \mathrm{I}\right] \mathrm{b}-\mathrm{PTH}$ tracer binding to the $\mathrm{CH} 9$ antiserum with increasing amounts of unlabeled b-PTH (-๑) and syn b-PTH 1-34 (O--O) and displacement of tracer binding to the $\mathrm{CH} 9$ antiserum preadsorbed with syn b-PTH 1-34 with increasing amounts of b-PTH $(\boldsymbol{\Delta}-\boldsymbol{\Delta})$ and syn b-PTH $(\Delta--\triangle)$.

Metabolism of Parathyroid Hormone 
terminal portion of PTH was 10-fold less when these sites were present as a portion of the intact molecule rather than the 1-34 fragment itself.

The iodination of b-PTH and syn b-PTH 1-34 for use in the RIA was performed by the chloramine $\mathrm{T}$ method of Greenwood, Hunter, and Glover (21) using a ratio of 1.3 $\mu \mathrm{g}$ of b-PTH and $2.9 \mu \mathrm{g}$ of syn b-PTH $1-34$ per $\mathrm{mCi}$ of iodine and an 8:1 ratio of chloramine $\mathrm{T}$ to $\mathrm{PTH}$ in the reaction mixture. Iodinated hormones were separated from free ${ }^{131} \mathrm{I}$ and damaged peptides by adsorption onto and elution from Quso (22) followed by elution from a $1 \times 30$ $\mathrm{cm}$ column of Bio-Gel P-10 with $10 \%$ human plasma in 0.1 $\mathrm{M}$ barbital buffer, $\mathrm{pH} 8.5$, as the column vehicle. The specific activities of $\left[{ }^{131} \mathrm{I}\right] \mathrm{b}-\mathrm{PTH}$ obtained by this iodination procedure ranged between $250-450 \mu \mathrm{Ci} / \mu \mathrm{g}$ and for syn $\mathrm{b}$ PTH 1-34 were $100-250 \mu \mathrm{Ci} / \mu \mathrm{g}$.

RIA was performed by adding serum samples, standards, and $100 \mu \mathrm{l}$ of the antiserum in the dilution noted below and incubating at $4^{\circ} \mathrm{C}$ for 3-4 days with constant agitation before adding $10-12,000 \mathrm{cpm}$ of labeled hormone and reincubating for an additional $36-48 \mathrm{~h}$ in the cold. After incubation, charcoal dextran separation was used to separate bound from free hormone (23). The charcoal dextran suspension contained $6.3 \mathrm{~g} /$ liter of neutralized activated charcoal and $0.63 \mathrm{~g} /$ liter Dextran T-70 (Pharmacia Fine Chemicals Inc., Piscataway, N. J.) dissolved and mixed at $4^{\circ} \mathrm{C}$ in a $0.85 \% \mathrm{NaCl}$, sodium barbital $0.007 \mathrm{M}$, and sodium

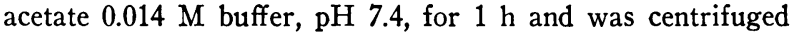
at $2,000 \mathrm{rpm}$ for $15 \mathrm{~min}$, decanted, then reconstituted in the suspension buffer with $250 \mathrm{mg} /$ liter of human albumin added. The suspension was mixed at $4^{\circ} \mathrm{C}$ overnight and added to assay tubes in the cold. After addition of the charcoal-dextran solution assay tubes were vortexed, centrifuged, and supernate carefully decanted into clean test tubes. ${ }^{131}$ I radioactivity in both bound and free fractions was counted in a gamma well spectrophotometer (Packard Instruments, Inc., Downer's Grove, Ill.).

All serum samples were tested in multiple dilutions in duplicate. Appropriate controls without added antiserum

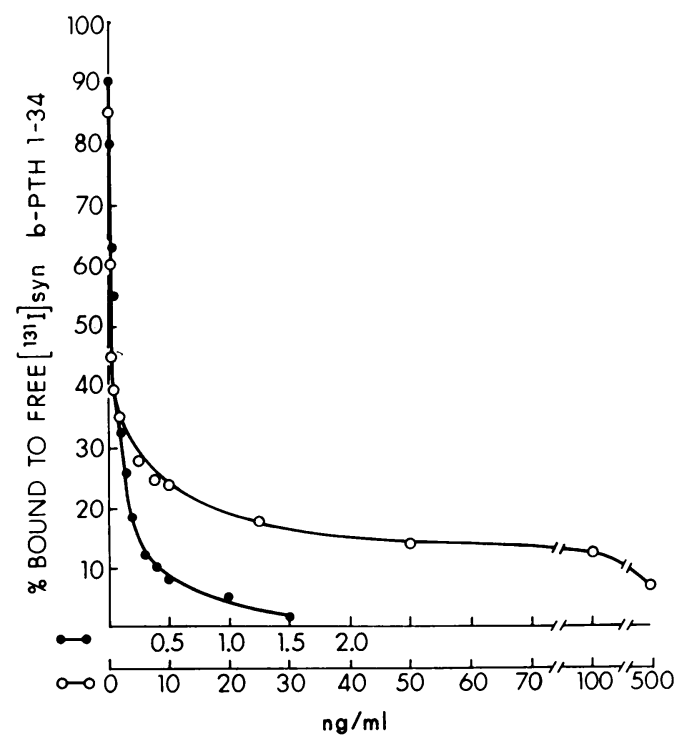

Figure 2 Displacement of $\left[{ }^{131} \mathrm{I}\right]$ syn b-PTH tracer binding to the CH9N antiserum with increasing amounts of unlabeled syn b-PTH 1-34 (-๑) and b-PTH (O-O). were used in every assay to correct for nonspecific binding and/or effects due to incubation damage of radioiodinated hormone. Also, controls for antibody binding to labeled hormone in the absence of unlabeled hormone or sample (trace binding) at several different serum protein concentrations were included in each assay. Each test sample was related to the control and tracer binding with the same protein concentration.

The antiserum dilution of $1: 15,000$ was used for $\mathrm{CH} 9$ and routinely gave a $\mathrm{B} / \mathrm{F}$ (bound to free) ratio of $0.7-0.9$ when incubated with labeled hormone in absence of unlabeled hormone. The $\mathrm{CH} 9$ antiserum was used in the determination of the clearance rates for b-PTH and thus these determinations reflect the metabolism of both intact $\mathrm{b}-\mathrm{PTH}$ and the major circulating PTH fragments. The $\mathrm{CH} 9$ antiserum preadsorbed with syn b-PTH 1-34 was used in gel filtration studies, and binding to the antiserum was thus limited to $\mathrm{C}$-terminal binding sites. Analysis of variance between sample replicates was less than $10 \%$ at all times. The antiserum dilution of $1: 8,000$ used for $\mathrm{CH} 9 \mathrm{~N}$ routinely gave $\mathrm{B} / \mathrm{F}$ ratios of $0.4-0.6$ when reacted with $\left[{ }^{131} \mathrm{I}\right]$ syn b-PTH 1-34 in the absence of unlabeled hormone or sample. The $\mathrm{CH} 9 \mathrm{~N}$ antiserum was used in gel filtration studies to determine the elution pattern of $\mathrm{N}$-terminal immunoreactivity and in the clearance studies for syn b-PTH 1-34. The standard used in these assays was syn b-PTH 1-34.

Gel filtration of serum pools. Arterial serum samples obtained during set intervals (0-15 $\mathrm{min}, 15-50 \mathrm{~min}$, and 50-180 min) of the PTH disappearance curve in normal and uremic dogs were pooled and in addition the $50-180-\mathrm{min}$ pools from normal dogs were concentrated according to methods described by Canterbury, Levey, and Reiss (10). Samples of serum pools were then placed on $1.5 \times 60-90-\mathrm{cm}$ columns of Bio-Gel P-10 (Bio-Rad Laboratories, Richmond, Calif.) and filtered along with column markers of $\left[{ }^{131} \mathrm{I}\right] \mathrm{b}-\mathrm{PTH}$ (Inolex Pharmaceuticals) and ${ }^{131} \mathrm{I}$ or $\left[{ }^{125} \mathrm{I}\right] \mathrm{syn}$ b-PTH 1-34 (Beckman Instruments, Inc.). Column eluant consisted of outdated blood bank plasma diluted $1: 10$ with $0.1 \mathrm{M}$ sodium barbital, $\mathrm{pH}$ 8.5. Void volume was determined by the elution position of blue dextran, mol wt 2 million, and the salt volume was determined by the elution of ${ }^{131} \mathrm{I}$. Column eluant was collected in $1-\mathrm{ml}$ fraction volumes. The immunoreactive PTH in each fraction was determined in assays employing the $\mathrm{CH} 9$ antiserum preadsorbed with syn b-PTH 1-34 and the $\mathrm{CH} 9 \mathrm{~N}$ antiserum. Thus, the elution pattern of both $\mathrm{C}$-terminal and $\mathrm{N}$-terminal immunoreactivity was determined.

Calculations. Creatinine clearance served as an index of glomerular filtration rate. Renal plasma flow was determined employing para-aminohippurate extraction across the kidney and the Wolff modification of the Fick principle (24). The renal extraction of immunoreactive $\mathrm{PTH}$ and syn b-PTH 1-34 was determined from A-V differences across the kidney and the renal clearance of both substances was determined by the product of their respective extraction rates and the renal plasma flow. The result was expressed in volume of serum cleared of PTH by the kidney per unit time (milliliters per minute). MCR rates were determined by both single injection and constant infusion techniques according to methods described by Tait (25). In the single injection technique, the disappearance curve was multiexponential. A three exponential system routinely demonstrated the best curve fitting by the least squares method and was used for the determination of MCR. Analysis of the disappearance curve was performed on an IBM S/360 computer employing the SAAM program of 
TABLE I

Studies in Normal and Uremic Dogs with b-PTH

\begin{tabular}{|c|c|c|c|c|c|c|c|c|c|}
\hline Dog no. & $\begin{array}{l}\text { b-PTH } \\
\text { injected }\end{array}$ & GFR & RPF & PAH ext & PTH ext & $\mathrm{RC}$ & MCR & $\mathrm{RC} / \mathrm{MCR}$ & MCR-RC \\
\hline & $\mu g$ & $\mathrm{ml} / \mathrm{min}$ & $\mathrm{ml} / \mathrm{min}$ & $\%$ & $\%$ & $m l / m i n$ & $m l / m i n$ & $\%$ & $\mathrm{ml} / \mathrm{min}$ \\
\hline 1 & 50 & 66 & 259 & 77 & 21 & 54 & 90 & 60 & 36 \\
\hline 2 & 45 & 89 & 361 & 82 & 22 & 79 & 134 & 49 & 55 \\
\hline 3 & 100 & 57 & 232 & 75 & 15 & 35 & 59 & 59 & 24 \\
\hline 4 & 100 & 90 & 402 & 81 & 23 & 93 & 147 & 63 & 54 \\
\hline 5 & 100 & 86 & 256 & 87 & 24 & 61 & 105 & 48 & 44 \\
\hline \multirow[t]{2}{*}{6} & 27 & 73 & 295 & 81 & 16 & 47 & 67 & 70 & 20 \\
\hline & 100 & 13 & 96 & 43 & 12 & 12 & 30 & 40 & 18 \\
\hline \multirow[t]{2}{*}{7} & 50 & 76 & 304 & 79 & 17 & 52 & 87 & 60 & 35 \\
\hline & 50 & 12 & 93 & 50 & 15 & 14 & 48 & 29 & 34 \\
\hline 8 & 50 & 6 & 35 & 65 & 28 & 10 & 38 & 26 & 28 \\
\hline 9 & 50 & 21 & 114 & 60 & 16 & 18 & 33 & 55 & 15 \\
\hline 10 & 30 & 8 & 81 & 40 & 20 & 16 & 30 & 53 & 14 \\
\hline 11 & 30 & 4 & 93 & 50 & 15 & 14 & 48 & 29 & 34 \\
\hline \multirow{2}{*}{\multicolumn{2}{|c|}{$\begin{array}{l}\text { Mean (Normal) } \\
\pm \text { SEM }\end{array}$}} & 77 & 301 & 80 & 20 & 60 & 98 & 61 & 38 \\
\hline & & 5 & 23 & 2 & 1 & 8 & 12 & 2 & 5 \\
\hline \multirow{2}{*}{\multicolumn{2}{|c|}{$\begin{array}{l}\text { Mean (CRD) } \\
\pm \text { SEM }\end{array}$}} & 11 & 77 & 51 & 19 & 13 & 36 & 38 & 23 \\
\hline & & 3 & 13 & 4 & 2 & 1 & 3 & 6 & 3 \\
\hline
\end{tabular}

CRD, chronic renal disease; GFR, glomerular filtration rate; RPF, renal plasma flow; PAH ext, para-aminohippurate extraction; PTH ext, parathyroid hormone extraction; RC/MCR, renal clearance divided by total MCR, i.e., the percent contribution of the kidney to total MCR; MCR-RC, total metabolic clearance minus renal clearance, i.e., the extrarenal clearance of immunoreactive PTH.

Berman, Shahn, and Weiss (26). MCR was calculated from the area under the disappearance curve employing the appropriate integration formula for a three exponential system :

$$
\mathrm{MCR}=\mathrm{R} \cdot \frac{1}{\frac{\mathrm{A}}{\alpha}+\frac{\mathrm{B}}{\beta}+\frac{\mathrm{C}^{\prime}}{\gamma}}
$$

where $\mathrm{R}$ represents total dose of $\mathrm{PTH}$ administered and $\mathrm{A}, \mathrm{B}$, and $\mathrm{C}$, are values for the $y$ intercept of each exponent and $\alpha, \beta$, and $\gamma$ are values for the slope of each exponent. Calculation of MCR in constant infusion studies was performed by the formula: MCR = infusion rate (ng/ $\mathrm{min}) /$ arterial concentration $(\mathrm{ng} / \mathrm{ml})$. Results from both single injection and constant infusion techniques were similar and, therefore, most studies were performed by the single injection technique. Where both types of studies were performed the data portrayed for MCR represents a mean of the results in both single injection and constant infusion studies.

The data for MCR and renal clearance (RC) rates represent clearances of immunoreactivity. In the case of studies involving the administration of b-PTH, they represent the combined disappearance rate of intact b-PTH and its Cterminal fragments, as determined in assays with the $\mathrm{CH} 9$ antiserum. The $\mathrm{CH} 9$ antiserum binds intact hormone through mainly C-terminal binding sites and with nearly equal affinity for these sites as either intact hormone or as C-terminal fragments. Thus, the injected b-PTH was recognized similarly throughout its disappearance curve. However, because of the change from intact hormone to $\mathrm{C}$ - terminal fragments, the calculation of MCR on the basis of immunoreactivity determined in assays with the $\mathrm{CH} 9$ antiserum can only be considered an estimate of overall turnover rate of immunoreactivity for comparison to the renal turnover rate and not as the metabolic turnover rate for intact PTH.

In the case of the studies after the administration of syn b-PTH 1-34, the CH9N antiserum did not detectably bind with products of degradation as determined by gel filtration studies. Therefore, the disappearance rate of immunoreactive syn b-PTH 1-34, as determined by RIA using the $\mathrm{CH} 9 \mathrm{~N}$ antiserum, represents determination of the MCR rate of this hormonal species.

\section{RESULTS}

Studies with $b-P T H$. The results of experiments performed in seven normal dogs and six dogs with chronic renal insufficiency during the administration of b-PTH are shown in Table I. Two dogs (6 and 7) were studied as normal and with chronic renal disease. Mean GFR was $77 \pm 5 \mathrm{ml} / \mathrm{min}$ in normal dogs with a range of $57-90 \mathrm{ml} / \mathrm{min}$. The GFR and RPF in the uremic animals was $11 \pm 3 \mathrm{ml} / \mathrm{min}$ and $77 \pm 13 \mathrm{ml} / \mathrm{min}$, respectively. $\mathrm{PAH}$ extraction was consistently between $75-85 \%$ in the normal dogs but varied to a greater extent in the uremic animals.

The renal extraction of immunoreactivity after the injection of b-PTH appeared to be constant at widely varying $\mathrm{PTH}$ concentrations in both uremic and normal 


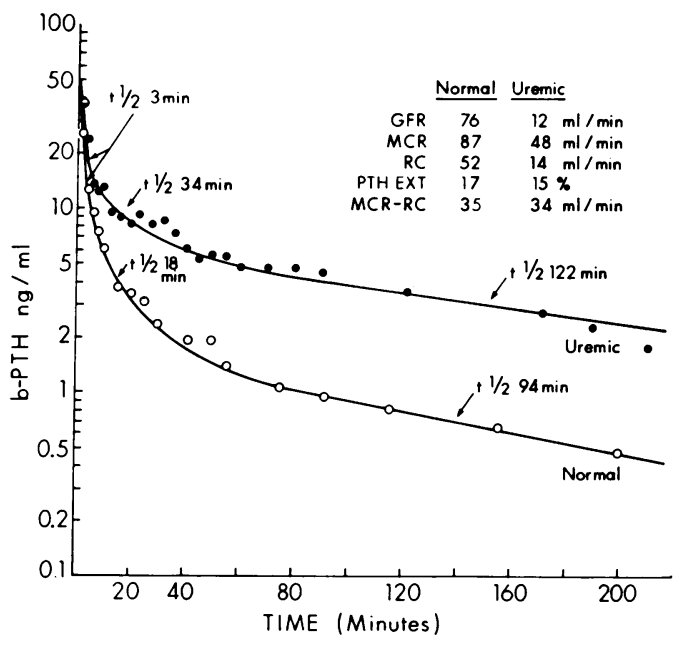

FIGURE 3 Disappearance curves of immunoreactive PTH after injection of b-PTH as measured by the CH9 antiserum in a dog studied when normal $(\mathrm{O}-\mathrm{O})$ and after the induction of uremia $(-\bullet)$. T $\frac{1}{2}$ refers to half-time of disappearance during each of three exponents in the disappearance curve. See text for additional details.

dogs, and in single injection studies percent extraction was constant throughout the entire disappearance curve. Renal extraction was $20 \pm 1 \%$ (range 15-24\%) in normal dogs, as determined in assays with the CH9 antiserum, and was $19 \pm 2 \%$ (range 12-28\%) in uremic dogs. Despite the fact that the percent of extraction of delivered immunoreactive PTH was not affected by the induction of uremia, the $\mathrm{RC}$ of immunoreactivity was markedly diminished from a mean of $60 \pm 8 \mathrm{ml} / \mathrm{min}$ in normal dogs to $13 \pm 1 \mathrm{ml} / \mathrm{min}$ in uremic animals. Urinary excretion of immunoreactive $\mathrm{PTH}$ accounted for less than $1 \%$ of the $\mathrm{RC}$ of $\mathrm{PTH}$ in both normal and uremic animals, ranging from 0.1 to $0.5 \%$ of the injected dose. The decrease in RC of immunoreactive $\mathrm{b}-\mathrm{PTH}$ seen in dogs with reduced renal function was directly related to a decrease in renal plasma flow.

Estimations of the total MCR of immunoreactivity also decreased with the induction of chronic renal disease from $98 \pm 12 \mathrm{ml} / \mathrm{min}$ in normal dogs to $36 \pm 3 \mathrm{ml}$ / min in uremic dogs. Most of the decrease in total MCR was accounted for by the decrease in RC (74\%), as demonstrated by the significant drop in the renal contribution ( $\mathrm{RC} / \mathrm{MCR}$ ) to the total MCR from $61 \%$ in normals to $38 \%$ in uremic dogs. There was also a small decrease in mean extrarenal immunoreactive $\mathrm{PTH}$ clearance (MCR-RC) despite overlap between the normal and uremic dogs in individual instances.

Fig. 3 portrays the disappearance curve of immunoreactive b-PTH in a dog that was studied in both normal and uremic states. The renal function and PTH clearance data are represented in the upper right corner. The disappearance curve for PTH is clearly multiex- ponential in both normal and uremic states. The initial rapid disappearance with a half-time of 2-3 min appears similar in both normal and chronic renal disease states, but after this initial rapid disappearance rate the curves diverge with the uremic curve having a much longer half-time of disappearance.

To follow the alterations in the circulating form of $\mathrm{PTH}$ during the time of the disappearance curve and to detect the appearance and disappearance of $\mathrm{PTH}$ fragments, serum samples collected during set intervals of the disappearance curve $(0-15 \mathrm{~min}, 15-50 \mathrm{~min}$, and 50-180 min) were pooled and filtered through Bio-Gel $\mathrm{P}-10$. The elution pattern of C-terminal immunoreactivity was determined by RIA of the column fractions employing the $\mathrm{CH} 9$ antiserum preadsorbed with syn b-PTH 1-34, and the elution pattern of $\mathrm{N}$-terminal was determined by RIA using the CH9N antiserum. Fig. 4 portrays a representative elution pattern of the three serum pools from a normal dog. Immunoreactivity in the area of the b-PTH marker accounted for the

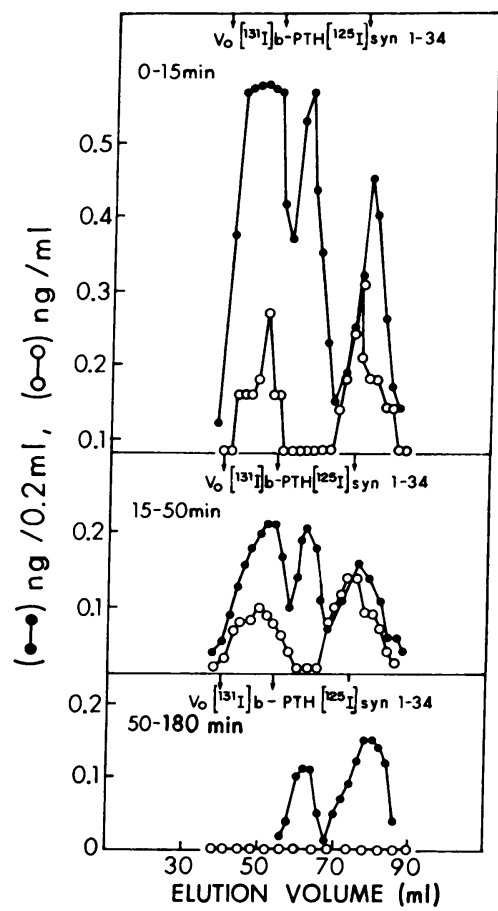

FIGURE 4 Elution patterns of immunoreactive $\mathrm{PTH}$ as measured in three serum pools collected during the intervals $0-15 \mathrm{~min}, 15-50 \mathrm{~min}$, and $50-180 \mathrm{~min}$ after administra-

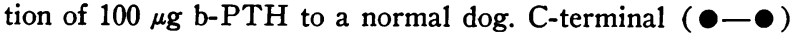
immunoreactivity was determined in assays with the $\mathrm{CH} 9$ antiserum preadsorbed with syn b-PTH 1-34. N-terminal immunoreactivity $(\mathrm{O}-\mathrm{O}$ ) was determined in assays with the CH9N antiserum. Gel filtration was performed through a $1.5 \times 60-\mathrm{cm}$ column of Bio-Gel P-10. Not shown is the elution position of ${ }^{131} \mathrm{I}$ (salt volume) which was $180 \mathrm{ml}$ in these experiments. $V_{0}$, void volume. 
TABLE II

Studies in Normal and Uremic Dogs with syn b-PTH 1-34

\begin{tabular}{|c|c|c|c|c|c|c|c|c|c|}
\hline Dog no. & $\begin{array}{c}\text { syn } \\
\text { b-PTH } \\
1-34 \\
\text { injected }\end{array}$ & GFR & RPF & PAH ext & $\begin{array}{c}\text { syn } \\
\text { b-PTH } \\
1-34 \\
\text { ext }\end{array}$ & RC & MCR & $\mathrm{RC} / \mathrm{MCR}$ & MCR-RC \\
\hline & $\mu g$ & $\mathrm{ml} / \mathrm{min}$ & $\mathrm{ml} / \mathrm{min}$ & $\%$ & $\%$ & $\mathrm{ml} / \mathrm{min}$ & $\mathrm{ml} / \mathrm{min}$ & $\%$ & $\mathrm{ml} / \mathrm{min}$ \\
\hline 1 & 95.2 & 82 & 347 & 76 & 45 & 156 & 299 & 52 & 143 \\
\hline 2 & 100 & 73 & 276 & 70 & 41 & 113 & 248 & 46 & 135 \\
\hline 3 & 100 & 64 & 248 & 70 & 38 & 94 & 192 & 49 & 98 \\
\hline \multirow[t]{2}{*}{4} & 100 & 57 & 261 & 80 & 33 & 86 & 223 & 39 & 137 \\
\hline & 100 & 23 & 106 & 50 & 34 & 36 & 57 & 63 & 21 \\
\hline \multirow[t]{2}{*}{5} & 50 & 66 & 333 & 70 & 28 & 93 & 247 & 38 & 154 \\
\hline & 50 & 5 & 56 & 31 & 25 & 14 & 87 & 16 & 73 \\
\hline 6 & 95.2 & 17 & 83 & 76 & 19 & 16 & 129 & 12 & 113 \\
\hline 7 & 50 & 20 & 88 & 67 & 50 & 44 & 105 & 42 & 61 \\
\hline 8 & 50 & 16 & 88 & 67 & 26 & 23 & 45 & 51 & 22 \\
\hline 9 & 95.2 & 10 & 59 & 44 & 20 & 12 & 72 & 17 & 60 \\
\hline \multirow{2}{*}{\multicolumn{2}{|c|}{$\begin{array}{l}\text { Mean (Normal) } \\
\pm \text { SEM }\end{array}$}} & 68 & 293 & 73 & 37 & 108 & 241 & 45 & 133 \\
\hline & & 4 & 20 & & 3 & 13 & 18 & 3 & 9 \\
\hline \multirow{2}{*}{\multicolumn{2}{|c|}{$\begin{array}{l}\text { Mean (CRD) } \\
\pm \text { SEM }\end{array}$}} & 15 & 80 & 56 & 29 & 24 & 83 & 34 & 58 \\
\hline & & 3 & 8 & 7 & 5 & 5 & 13 & 9 & 14 \\
\hline
\end{tabular}

syn b-PTH 1-34 ext, the extraction of bovine synthetic N-terminal tetratricontapeptide.

See Table I for other abbreviations.

great portion of immunoreactive $\mathrm{PTH}$ eluting from the column in the first pool (0-15 min) but rapidly disappeared so that it was undetectable in the pool of samples from $50-180 \mathrm{~min}$. There was early production of two smaller molecular weight fragments detected in assays with the $\mathrm{CH} 9$ antiserum representing fragments with C-terminal binding sites; the first eluted between the b-PTH 9,500 mol wt marker and the syn b-PTH 1-34 4,500 mol wt marker, and the second eluted at the same point as the $4,500 \mathrm{~mol}$ wt marker. These fragments represented the bulk of the circulating PTH after $50 \mathrm{~min}$. Peaks of $\mathrm{N}$-terminal immunoreactivity eluting in the same area as the b-PTH and syn b-PTH 1-34 markers were demonstrated by the $\mathrm{CH} 9 \mathrm{~N}$ antiserum. The peak of $\mathrm{N}$-terminal immunoreactivity in the area of the syn b-PTH 1-34 marker was present in the largest amount in the $0-15-\mathrm{min}$ pool but was undetectable in concentrated serum pools past $50 \mathrm{~min}$. Pooling of the serum samples from the three periods of the disappearance curve and gel filtration of the pools was performed on samples from three normal dogs, and all patterns were similar to those portrayed in Fig. 4.

Fig. 5 portrays the elution pattern of immunoreactive PTH for both C- and N-terminal regions in three serum pools from a dog with chronic renal disease. The PTH fragments detected in these gel filtration studies were qualitatively similar to the fragments seen in the pools from normal dogs; i.e., a C-terminal fragment eluting between the 9,500 and 4,500 mol wt markers, a C-terminal fragment eluting with the $4,500 \mathrm{~mol} \mathrm{wt}$ marker, and an N-terminal fragment eluting with the $4,500 \mathrm{~mol} \mathrm{wt}$ marker. The amount of immunoreactivity in each pool from the chronic renal disease dogs was greater than the amount present in corresponding pools from normal dogs. This was especially the case for C-terminal fragments eluting with the $4,500 \mathrm{ml}$ wt marker. The gel filtration of pooled serum samples was performed on samples from two dogs with chronic renal disease each giving similar results.

Studies with syn b-PTH 1-34. To examine further the metabolism of the $\mathrm{N}$-terminal fragment, studies were performed in five normal and five uremic dogs after injection of the biologically active syn b-PTH 1-34. Studies were performed in the same manner as the studies above with intact b-PTH. Table II shows the results of renal function and PTH clearances in normal (no. 1-5) and uremic (no. 4-9) dogs. Glomerular filtration rate, renal plasma flow, and $\mathrm{PAH}$ extraction were comparable to the studies portrayed in Table I.

The renal extraction of immunoreactive syn b-PTH 1-34 was higher than it was for administered b-PTH, $37 \pm 3 \%$ vs. $20 \pm 1 \%$, respectively, in normal dogs. The extraction of syn b-PTH 1-34 was not significantly decreased by the induction of uremia; $37 \pm 3 \%$ of delivered syn b-PTH 1-34 was extracted in normal dogs and $29 \pm 5 \%$ in uremic animals $(P>0.1)$. RC of immuno- 


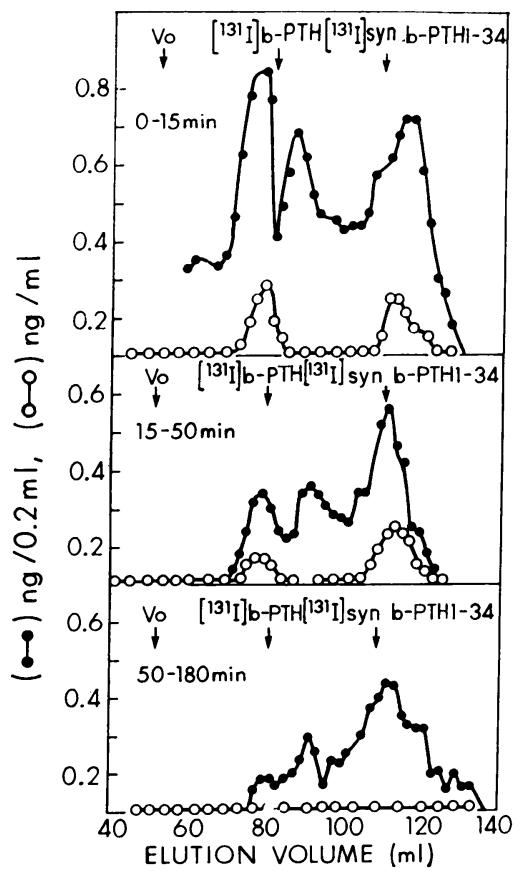

FIgURE 5 Elution patterns of immunoreactive PTH in a dog with chronic renal disease determined as in Fig. 4, (C-terminal immunoreactivity $(\bullet-\bullet), \mathrm{N}$-terminal immunoreactivity (O-O).) Gel filtration performed through $1.5 \times 90-\mathrm{cm}$ columns of Bio-Gel P-10. Not shown is the elution position of ${ }^{131} \mathrm{I}$ (salt volume) which was $225 \mathrm{ml}$ in these experiments.

reactive syn b-PTH 1-34 decreased significantly from $108 \pm 13 \mathrm{ml} / \mathrm{min}$ in normal dogs to $24 \pm 5 \mathrm{ml} / \mathrm{min}$ in uremia. This change was related to the fall in renal plasma flow as in the studies with b-PTH. The mean total MCR for immunoreactive syn b-PTH 1-34 was $241 \pm 18 \mathrm{ml} / \mathrm{min}$ in normal dogs and decreased to $83 \pm 13$ $\mathrm{ml} / \mathrm{min}$ in the uremic animals. While the decrease in $\mathrm{RC}$ contributed to the decrease in the total MCR, there was also a marked decrease in extrarenal clearance of syn b-PTH 1-34. RC accounted for 45\% of the total MCR in normals and this contribution was decreased by uremia $(34 \%)$. Thus, for syn b-PTH 134 the decrease in total MCR was accounted for by decreases in both renal and extrarenal clearances.

The disappearance curves for syn b-PTH 1-34 in a dog studied both in the normal and uremic state are portrayed in Fig. 6. The renal function and PTH clearances are listed in the upper right corner of the figure. As was the case for the disappearance curves of intact $\mathrm{PTH}$, the uremic and normal disappearance curves for syn b-PTH 1-34 appear not to differ in the first 1-4 min but then diverge widely with slower rates of decay in the uremic state. The disappearance curves for synb-PTH 1-34 are multiexponential, as they were for intact PTH, but the rate of disappearance was much more rapid, so that after the injection of $100 \mu \mathrm{g}$ of syn b-PTH 1-34, the blood level was less than $0.2 \mathrm{ng} / \mathrm{ml}$ by $90 \mathrm{~min}$ in normal dogs.

\section{DISCUSSION}

The present studies describe the role of the canine kidney in the metabolism of PTH in vivo. The normal dog kidney extracted approximately $20 \%$ of the immunoreactive b-PTH delivered to it. The RC of immunoreactive PTH was $60 \mathrm{ml} / \mathrm{min}$. When the RC of immunoreactivity was compared to the calculated MCR, it accounted for $61 \%$ of the total. In chronic renal disease, the percent extraction of delivered immunoreactive PTH was unchanged from the normal state, but RC was markedly diminished due to the decrease in renal plasma flow in the diseased kidney. Total MCR rate of immunoreactivity was also severely depressed in uremia, and the decrease in RC accounted for a large portion (circa $74 \%$ ) of the decrease in total MCR. The data suggest that the renal removal of PTH from the circulation is related to functioning renal mass. In uremia, the functioning mass is decreased, thus the decrease in $\mathrm{RPF}, \mathrm{MCR}$, and $\mathrm{RC}$, but the remaining mass appears to function normally judging from the unimpaired extraction rate for $\mathrm{PTH}$.

The term MCR in the studies after the administration of b-PTH represents a turnover rate of immunoreactivity. Because the $\mathrm{CH} 9$ antiserum binds with equal affinity to intact hormone and C-terminal fragments, the MCR term is a combination of the disappearance of intact b-PTH and C-terminal fragments. The term was used to relate the $\mathrm{RC}$ as determined in assays with the $\mathrm{CH} 9$ antiserum to a total turnover rate. The usefulness of the MCR for b-PTH as a measure of the turnover rate of $\mathrm{PTH}$, as determined through RIA's using

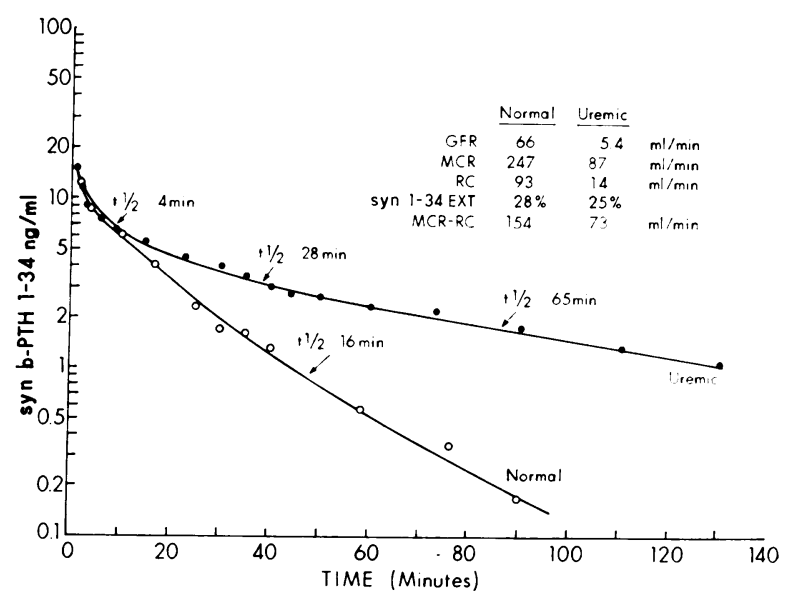

FIgURE 6 Disappearance curves of immunoreactive PTH after injection of syn b-PTH 1-34 as measured by the $\mathrm{CH} 9 \mathrm{~N}$ antiserum in a dog studied when normal (O-O) and after induction of chronic renal disease $(\bullet-\bullet)$. 
the $\mathrm{CH} 9$ antiserum, is restricted since it would vary with the use of different antisera in the RIA.

Studies performed after administration of syn b-PTH 1-34 demonstrated results similar to those obtained with intact b-PTH. Uremia did not affect extraction of syn b-PTH 1-34 significantly, but again RC was markedly diminished because of decreased blood flow to the diseased organ. However, the studies performed with syn b-PTH 1-34 in uremic dogs demonstrated a marked decrease in extrarenal clearance of immunoreactive $\mathrm{N}$-terminal fragment as compared to normal dogs, more clearly demonstrating the effects of uremia on extrarenal sites of $\mathrm{PTH}$ degradation than was seen in the studies with intact b-PTH. The effect of uremia on extrarenal PTH metabolism has not been previously described, and the studies reported here do not indicate the site of the defective extrarenal clearance. Previous studies indicating that the kidney and the liver $(27,28)$ are the main sites of peripheral PTH metabolism would suggest that the liver may be the extrarenal site of degradation affected by uremia. There is no available experimental data relating the metabolism of the synthetic N-terminal of PTH used in these studies to the metabolism of the native $\mathrm{N}$-terminal of PTH; and thus, the results of the studies of the metabolism of syn b-PTH 1-34 do not of necessity reflect the metabolism of native N-terminal. Some of the limitations of the MCR as described above for b-PTH do not hold for the MCR of syn b-PTH 1-34 since products of degradation did not appear to bind significantly with the $\mathrm{CH} 9 \mathrm{~N}$ antiserum.

The disappearance curves for both intact b-PTH and syn b-PTH 1-34 were multiexponential in the single injection studies reported herein. There was an initial rapid phase in both b-PTH and syn b-PTH 1-34 disappearance curves, and chronic renal disease did not appear to have a detectable effect on this early phase of $\mathrm{PTH}$ disappearance. However, after the early rapid phase, normal and uremic PTH disappearance curves diverged with longer half-times of PTH removal in the uremic state.

Gel filtration of the circulating $\mathrm{PTH}$ in pooled arterial serum samples from normal dogs, taken at set intervals during the disappearance curve of b-PTH, indicate rapid disappearance of the intact molecule and appearance of both $\mathrm{C}$ - and $\mathrm{N}$-terminal PTH fragments. The C-terminal fragments tended to persist in the circulation and $50 \mathrm{~min}$ after the injection of $\mathrm{PTH}$ represented the major species in the circulation. The elution patterns of gel filtration studies on pooled arterial serum from chronic renal disease dogs were similar to those of normal dogs, except that the amount of immunoreactivity was greater in each pool. This was especially prominent for C-terminal immunoreactivity eluting after the intact PTH marker.
The amount of $\mathrm{N}$-terminal immunoreactivity that chromatographed with the b-PTH marker can be accounted for by the ability of the $\mathrm{CH} 9 \mathrm{~N}$ antiserum to bind with $\mathrm{N}$-terminal sites on the intact b-PTH molecule. The peak of $\mathrm{N}$-terminal immunoreactivity occurring with the syn b-PTH 1-34 marker indicates a circulating $\mathrm{N}$-terminal fragment present in low concentrations and detectable for a short time after the injection of a large amount of b-PTH. Immunoreactive PTH eluting with the syn b-PTH 1-34 marker that also demonstrated biological activity has been described in pooled concentrated plasma samples from patients with primary hyperparathyroidism (10), but N-terminal immunoreactivity in this area was not detected in studies from another laboratory (29). The reasons for these disparate results are not indicated by the present studies.

The studies described above demonstrate a marked decrease in the renal and total turnover rates of immunoreactive b-PTH and syn b-PTH 1-34 induced by chronic renal disease. They indicate that impaired degradation may be another factor, in addition to increased production rates, contributing to the high levels of $\mathrm{PTH}$ routinely seen in patients with chronic renal disease. Thus, in patients with renal failure the RIA for PTH may reflect not only overproduction of PTH, as it does for hyperparathyroid states without renal disease, but both overproduction and impaired degradation. Inasmuch as C-terminal fragments are the major detectable PTH species in the circulation and since their halflife is much longer than that of intact hormone or $\mathrm{N}$-terminal fragments, impaired degradation may be a significant factor in the levels of C-terminal fragments seen in chronic renal disease. Thus, the use of C-terminal assays as estimates of only increased $\mathrm{PTH}$ production rates in chronic renal disease may result in an overestimation.

\section{ACKNOWLEDGMENTS}

The authors wish to express their appreciation to Doctors Eric Reiss, Janet Canterbury, and Claude Arnaud for their kind assistance and advice in the development of the radioimmunoassays for PTH reported in this paper.

This work was supported by U. S. Public Health Service and National Institute of Arthritis and Metabolic Disease research grants AM-05248 and AM-09976.

\section{REFERENCES}

1. Slatopolsky, E., S. Caglar, J. P. Pennell, D. D. Taggart, J. M. Canterbury, E. Reiss, and N. S. Bricker. 1971. On the pathogenesis of hyperparathyroidism in chronic renal insufficiency in the dog. J. Clin. Invest. 50: $492-499$.

2. Slatopolsky, E., S. Caglar, L. Gradowska, J. Canterbury, E. Reiss, and N. S. Bricker. 1972. On the prevention of secondary hyperparathyroidism in experimental chronic renal disease using proportional reduc-

Metabolism of Parathyroid Hormone 
tion of dietary phosphorus intake. Kidney Int. 2: 147151.

3. Coburn, J. W., M. H. Koppel, A. S. Brickman, and S. G. Massry. 1973. Study of intestinal absorption of calcium in patients with renal failure. Kidney Int. 3: 264 272.

4. Martin, T. J., R. A. Melick, and M. deLuise. 1969. Metabolism of parathyroid hormone. Degradation of ${ }^{125}$ I-labeled hormone by a kidney enzyme. Biochem. J. $111: 509-514$.

5. Orimo, H., T. Fugita, H. Morii, and K. Nakao. 1965. Inactivation in vitro of parathyroid hormone activity by kidney slices. Endocrinology. 76: 255-258.

6. Melick, R. A., and T. J. Martin. 1969. Parathyroid hormone metabolism in man: effect of nephrectomy. Clin. Sci. (Oxf.). $37:$ 667-674.

7. Berson, S. A., and R. S. Yalow. 1968. Immunochemical heterogeneity of parathyroid hormone in plasma. J. Clin. Endocrinol. Metab. 28: 1037-1047.

8. Habener, J. F., G. V. Segre, D. Powell, T. M. Murray, and J. T. Potts, Jr. 1972. Immunoreactive parathyroid hormone in circulation of man. Nat. New Biol. 238: $152-154$.

9. Canterbury, J. M., and E. Reiss. 1972. Multiple immunoreactive molecular forms of parathyroid hormone in human serum. Proc. Soc. Exp. Biol. N. Y. 140: 1393-1398.

10. Canterbury, J. M., G. S. Levey, and E. Reiss. 1973. Activation of renal cortical adenylate cyclase by circulating immunoreactive parathyroid hormone fragments. J. Clin. Invest. 52: 524-527.

11. Silverman, R., and R. S. Yalow. 1973. Heterogeneity of parathyroid hormone. Clinical and physiologic implications. J. Clin. Invest. 52: 1958-1971.

12. Rhoads, C. P. 1934. A method for explantation of the kidney. Am. J. Physiol. 109: 324-328.

13. Bricker, N. S., S. Klahr, and R. E. Rieselbach. 1964. The functional adaptation of the diseased kidney. I. Glomerular filtration rate. J. Clin. Invest. 43: 1915-1921.

14. Aurbach, G. D., H. T. Keutmann, H. D. Niall, G. W. Tregear, J. L. H. O'Riordan, R. Marcus, S. J. Marx, and J. T. Potts, Jr. 1971. Recent Prog. Horm. Res. 28: 353-398.

15. Hawk, P. B., B. L. Oser, and W. H. Summerson. 1947. Practical Physiological Chemistry. The Blakiston Co., New York. 12th edition. 506.
16. Harvey, R. B., and A. J. Brothers. 1962. Renal extraction of paraaminohippurate and creatinine measured by continuous in vivo sampling of arterial and renalvein blood. Ann. N. Y. Acad. Sci. 102: 46-54.

17. Kraml, M. 1966. A semi-automated determination of phospholipids. Clin. Chim. Acta. 13: 442-448.

18. Hurst, R. O. 1967. A simplified approach to the use of determinants in the calculation of the rate equation for a complex enzyme system. Can. J. Biochem. 45: 20152039.

19. Reiss, E., and J. M. Canterbury. 1968. A radioimmunoassay for parathyroid hormone in man. Proc. Soc. Exp. Biol. Med. 128: 501-504.

20. Arnaud, C. D., H. S. Tsao, and T. Littledike. 1971 Radioimmunoassay of human parathyroid hormone in serum. J. Clin. Invest. 50: 21-34.

21. Greenwood, F. C., W. M. Hunter, and J. S. Glover 1963. The preparation of ${ }^{131}$ I-labeled human growth hormone of high specific radioactivity. Biochem. J. 89: 114-123.

22. Yalow, R. S., and S. A. Berson. 1966. Purification of ${ }^{131}$ I parathyroid hormone with microfine granules of precipitated silica. Nature (Lond.). 212: 357-358.

23. Herbert, V., K-S. Lau, C. W. Gottlieb, and S. J. Bleicher. 1965. Coated charcoal immunoassay of insulin. J. Clin. Endocrinol. Metab. 25: 1375-1384.

24. Wolf, A. V. 1950. The Urinary Function of the Kidney. Grune \& Stratton Inc., New York. 65.

25. Tait, J. F. 1963. Review: the use of isotopic steroids for the measurement of production rates in vivo. $J$. Clin. Endocrinol. Metab. 23: 1285-1297.

26. Berman, M., E. Shahn, and M. F. Weiss. 1962. The routine fitting of kinetic data to models: a mathematical formalism for digital computers. Biophys. J. 2: 275-287.

27. Zull, J. E., and D. W. Repke. 1972. The tissue localization of tritiated parathyroid hormone in thyroparathyroidectomized rats. J. Biol. Chem. 247: 2195-2199.

28. Fang, V. S., and A. H. Tashjian, Jr. 1972. Studies on the role of the liver in the metabolism of parathyroid hormone. I. Effects of partial hepatectomy and incubation of the hormone with tissue homogenates. Endocrinology. 90 : 1177-1184.

29. Segre, G. V., H. D. Niall, J. F. Habener, and J. T. Potts, Jr. 1974. Metabolism of parathyroid hormone. Physiologic and clinical significance. Am. J. Med. 56: 774-784. 